\title{
Smoking, alcohol and coffee consumption in Greek adolescents
} Areti Triantafyllou*1, Stefanos Tsotoulidis ${ }^{2}$, Mairi Dragoumi ${ }^{1}$, Andriana Kiritsi ${ }^{2}$, Aristidis Tsaxouridis ${ }^{2}$, Gesthimani Mintziori ${ }^{1}$ and Barsamis Papagewrgiou ${ }^{2}$

Address: ${ }^{1}$ Medical school, Aristotle university of Thessaloniki, Thessaloniki, Greece and ${ }^{2}$ Health Center of Kassandra, Halkidiki, Greece

* Corresponding author

from International Society on Brain and Behaviour: 3rd International Congress on Brain and Behaviour

Thessaloniki, Greece. 28 November - 2 December 2007

Published: 17 April 2008

Annals of General Psychiatry 2008, 7(SuppI I):S275 doi:I0.I I86/I744-859X-7-SI-S275

This abstract is available from: http://www.annals-general-psychiatry.com/content/7/SI/S275

(c) 2008 Triantafyllou et al.; licensee BioMed Central Ltd.

\section{Background}

The aim of this study, which was carried out between October and May of 2006-2007 was to determine the prevalence of smoking, alcohol and coffee consumption among the Greek adolescents (age 13-16) in Kassandra, in Greece.

\section{Materials and methods}

Of the 370 school students of Kassandra, prefecture Halkidiki, Greece, 315 agreed to answer in an anonymous questionnaire (response rate $85,2 \%$ ).

\section{Results}

$6.5 \%$ were smoking at least 5 cigarettes per day $(7.1 \%$ of the boys and $6 \%$ of the girls). All of the smokers were at least 16 years old ( $15.7 \%$ of the students of the lyceum) and they were smoking 18.53 (SD 13.9) cigarettes per day. According the alcohol consumption $27.1 \%$ were drinking at least one drink per week $(16.7 \%$ were in high school and $83.3 \%$ in lyceum, $\mathrm{p}<0.001$ ). $15 \%$ of the students they had to drink at least 4 drinks during entertainment and $6.1 \%$ they were drinking alcohol more than 3 days per week. $78.9 \%$ of the smokers were also drinking alcohol. Although 1 out of 3 adolescents they were drinking coffee, only $3.1 \%$ of them they were drinking 3 or more coffees per day. There weren't any statistical significant differences between the male and the females for any of the above variables.

\section{Conclusions}

Although the prevalence of smoking and alcohol consumption is lower than other epidemiological data, is still remaining high, indicating the need of the orientation of the local health system to educate and protect the adolescents of these hurtful conventions.

\section{Acknowledgements}

Efharis Panagopoulou, Medical school, Aristotle University of Thessaloniki,

\section{References}

I. Arvanitidou M, Tirodimos I, Kyriakidis I, Tsinaslanidou Z, Seretopoulos $D$ : Decreasing prevalence of alcohol consumption among greek adolescents. Am J Drug Alcohol Abuse 2007, 33(3):4I I-7.

2. Elisaf M, Papanikolaou N, Letzaris G, Siamopoulos KC: Smoking habit in female students of northwestern Greece: relation to other cardiovascular risk factors. J R Soc Health 1996, I I 6(2):87-90. Apr

3. Kokkevi A, Stefanis C: The epidemiology of licit and illicit substance use among high school students in Greece. Am J Public Health 1991, 81(1):48-52. Jan 